\title{
Comparison of pulmonary segmentectomy and lobectomy: Safety results of a randomized trial
}

\author{
Kenji Suzuki, MD, ${ }^{\text {a }}$ Hisashi Saji, MD, PhD,${ }^{b}$ Keiju Aokage, MD, PhD, ${ }^{\mathrm{c}}$ Shun-ichi Watanabe, MD, ${ }^{\mathrm{d}}$ \\ Morihito Okada, MD, PhD, ${ }^{\mathrm{e}}$ Junki Mizusawa, ME, ${ }^{\mathrm{f}}$ Ryu Nakajima, MD, ${ }^{\mathrm{g}}$ Masahiro Tsuboi, MD, PhD, \\ Shinichiro Nakamura, PhD, ${ }^{\mathrm{h}}$ Kenichi Nakamura, MD, ${ }^{\mathrm{f}}$ Tetsuya Mitsudomi, MD, ${ }^{\mathrm{i}}$ and Hisao Asamura, MD, \\ on behalf of the West Japan Oncology Group and Japan Clinical Oncology Group*
}

\section{ABSTRACT}

Background: No definitive comparisons of surgical morbidity between segmentectomy and lobectomy for non-small cell lung cancer have been reported.

Methods: We conducted a randomized controlled trial to confirm the noninferiority of segmentectomy to lobectomy in regard to prognosis (trial No. JCOG0802/ WJOG4607L). Patients with invasive peripheral non-small cell lung cancer tumor of a diameter $\leq 2 \mathrm{~cm}$ were randomized to undergo either lobectomy or segmentectomy. The primary end point was overall survival. Here, we have focused on morbidity and mortality. Predictors of surgical morbidity were evaluated by the mode of surgery. Segmentectomy was categorized into simple and complex. Simple segmentectomy was defined as segmental resection of the right or left segment 6 , left superior, or lingular segment. Complex segmentectomy was resection of the other segment. This trial is registered with the University Hospital Medical Information Network-Clinical Trial Registry (UMIN000002317).

Results: Between August 10, 2009, and October 21, 2014, 1106 patients (lobectomy $\mathrm{n}=554$ and segmentectomy $\mathrm{n}=552$ ) were enrolled. No mortality was noted. Complications (grade $\geq 2$ ) occurred in $26.2 \%$ and $27.4 \%$ in the lobectomy and segmentectomy arms $(P=.68)$, respectively. Fistula/pulmonary-lung (air leak) was detected in $21(3.8 \%)$ and $36(6.5 \%)$ patients in the lobectomy and segmentectomy arms $(P=.04)$, respectively. Multivariable analysis revealed that predictors of pulmonary complications, including air leak and empyema (grade $\geq 2$ ) were complex segmentectomy (vs lobectomy) (odds ratio, 2.07; $95 \%$ confidence interval, $1.11-3.88 ; P=.023)$, and $>20$ pack-years of smoking (odds ratio, 2.61; 95\% confidence interval, 1.14-5.97; $P=.023$ ).

Conclusions: There was no difference in almost any postoperative measure of intraoperative and postoperative complication in segmentectomy and lobectomy patients, except more air leakage was observed in the segmentectomy arm. Segmentectomy will be a standard treatment if the superior pulmonary function and noninferiority in overall survival are confirmed. (J Thorac Cardiovasc Surg 2019;158:895-907)

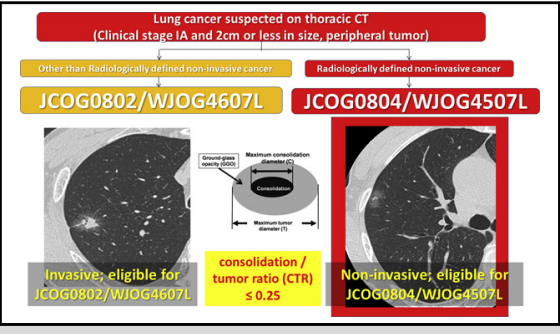

The 2 phase III trials, JCOG0802/NJOG4607L and JCOG0804/WJOG4507L, were based on JCOG0201.

\section{Central Message}

Segmentectomy and lobectomy for periphera lung cancer tumors $2.0 \mathrm{~cm}$ or smaller in size were feasible; however, segmentectomy was not less invasive than lobectomy in terms of postoperative air leak.

\section{Perspective}

Segmentectomy was not always less invasive than lobectomy and complex segmentectomy could result in frequent early postoperative pulmonary morbidity. Thus, although segmentectomy will be a standard treatment if the superior pulmonary function and its noninferiority in overall survival are confirmed, postoperative morbidity should be taken into consideration when deciding on an indication of segmentectomy.

See Commentaries on pages 908 and 909.

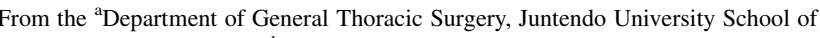
Medicine, Tokyo, Japan; ${ }^{\mathrm{b}}$ Department of General Thoracic Surgery, St Marianna University School of Medicine, Kanagawa, Japan; ${ }^{c}$ Division of Thoracic Surgery, National Cancer Center Hospital East, Chiba, Japan; ${ }^{\mathrm{d}}$ Division of Thoracic Surgery and ${ }^{\mathrm{f} J a p a n}$ Clinical Oncology Group Data Center/Operations Office, National Cancer Center Hospital, Tokyo, Japan; ${ }^{\mathrm{e}}$ Department of Thoracic Surgery, Hiroshima University Hospital, Hiroshima, Japan; ${ }^{\mathrm{g}}$ Department of Thoracic Surgery, Osaka

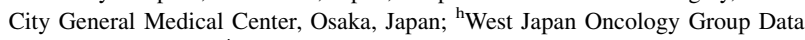

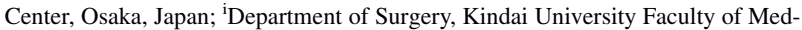
icine, Osaka, Japan; and ${ }^{\mathrm{j}}$ Division of Thoracic Surgery, Keio University School of Medicine, Tokyo, Japan.
}

Supported by the National Cancer Center, Ministry of Health,Labour and Welfare of Japan as well as grants from the Japan Agency for Medical Research and Development (Dr Mizusawa).

* Participating institutions are listed in the Acknowledgments.

Received for publication June 13, 2018; revisions received March 3, 2019; accepted for publication March 17, 2019; available ahead of print May 9, 2019

Address for reprints: Kenji Suzuki, MD, General Thoracic Surgery, Juntendo University School of Medicine, 1-3 Hongo 3 chome, Bunkyoku, Tokyo 113-843, Japan (E-mail: kjsuzuki@juntendo.ac.jp).

0022-5223/ $\$ 36.00$

Copyright (c) 2019 by The American Association for Thoracic Surgery

https://doi.org/10.1016/j.jtcvs.2019.03.090 


\section{Abbreviations and Acronyms}

CAT $=$ computer-assisted tomography

$\mathrm{C} / \mathrm{T}=$ consolidation tumor

GGO = ground glass opacity

JCOG = Japan Clinical Oncology Group

LCSG = Lung Cancer Study Group

LCSSG $=$ Lung Cancer Surgical Study Group

NSCLC $=$ non-small cell lung cancer

OS $=$ overall survival

WJOG = West Japan Oncology Group

Lung cancer continues to be the leading cause of cancer death in Japan and worldwide. ${ }^{1}$ Surgical resection is the mainstay for early stage lung cancers. ${ }^{2-4}$ During 1995 , the Lung Cancer Study Group (LCSG) showed a preference for lobectomy rather than sublobar resection in terms of local control and survival for patients with pathologic T1 N0 M0 non-small cell lung cancer (NSCLC). ${ }^{5}$ Since then, the standard mode of surgery has been lobectomy for early-stage lung cancer, despite recent improvement in survival after sublobar resection. . $^{5-7}$

Preoperative radiologic findings of ground glass opacity (GGO) on thin-section computer-assisted tomography (CAT) has been shown to predict prognosis fairly well. ${ }^{8-10}$ Based on the results of a prospective multi-institutional study on the relationship between radiologic and pathologic findings in peripheral lung cancer, the Lung Cancer Surgical Study Group (LCSSG) of the Japan Clinical Oncology Group (JCOG) defined a radiologically determined noninvasive lung cancer as a $\leq 2 \mathrm{~cm}$ lung cancer tumor with a consolidation tumor $(\mathrm{C} / \mathrm{T})$ ratio of 0.25 or less in diameter on thin-section CAT. ${ }^{10}$ Then, JCOG and the West Japan Oncology Group (WJOG) conducted a randomized, phase III trial on lobectomy versus limited resection (ie, segmentectomy) for small invasive peripheral lung cancers (JCOG0802/WJOG4607L) (Figure 1). ${ }^{11}$ The aim of JCOG0802/WJOG4607L was to confirm the noninferiority of segmentectomy compared with lobectomy regarding overall survival (OS). If noninferiority of segmentectomy is confirmed and superior postoperative pulmonary function of segmentectomy is shown, segmentectomy will become a standard surgery for this population. Here, we report on mortality and morbidity after segmentectomy.

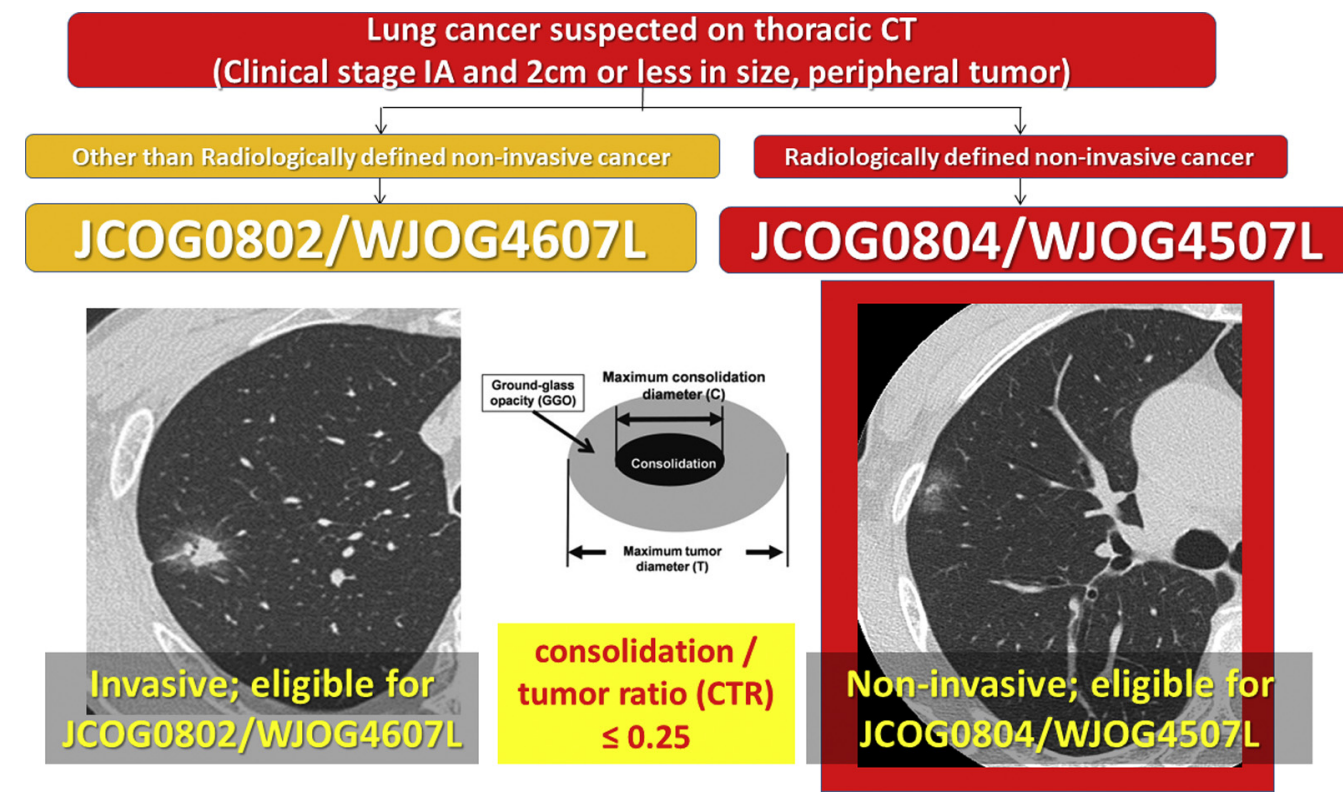

FIGURE 1. JCOG0201 concluded that radiologic noninvasive lung cancer was lung cancer $2 \mathrm{~cm}$ or less in size with consolidation tumor ratio 0.25 or less on thin-section computed tomography. Based on the definition, JCOG and WJOG conducted 2 independent clinical trials. JCOG0802/WJOG4607L was a randomized trial comparing lobectomy and segmentectomy for radiologic invasive lung cancer, and JCOG0804/WJOG4507L was a 1-arm multicenter prospective study for investigating the feasibility of wide wedge resection for radiologically noninvasive lung cancer defined by JCOG0201. JCOG, Japan Clinical Oncology Group; WJOG, West Japan Oncology Group; CTR, consolidation tumor ratio. 


\section{METHODS}

\section{Study Design and Patients}

A 2-step registration was used because the radiologic eligibility criteria are complex and histologic diagnosis of tumors was to be determined intraoperatively. Eligibility requirements at primary registration included age 20 to 85 years, an Eastern Cooperative Oncology Group performance score of 0 or 1, and a tumor of a clinically resectable NO NSCLC-suspected lesion. Patients underwent enhanced thoracic CAT within 56 days before the primary registration. Contrast-enhanced thoracic CAT had to fulfill all of the following conditions: single tumor, NSCLC suspected, center of tumor located in the outer one third of the lung field, tumor not located in the middle lobe, and no lymph node metastasis. Thin-section CAT was mandatory and had to fulfill both of the following conditions: maximum tumor diameter $\leq 2 \mathrm{~cm}$ and tumor with $\mathrm{C} / \mathrm{T}$ ratio $>0.5$. The protocol was revised 4 years after the start of enrollment to change the eligibility criterion from $\mathrm{C} / \mathrm{T}$ ratio $>0.25$ to $>0.5$ based on the results of a previous JCOG study (JCOG0201), in which the relapse-free survival of patients with a tumor $\leq 3 \mathrm{~cm}$ and a $\mathrm{C} / \mathrm{T}$ ratio $\leq 0.5$ was shown to be good enough (5-year relapse-free survival, $95.9 \%){ }^{8,10}$ Eligible patients had to have no history of prior ipsilateral thoracotomy, no prior chemo- and/or radiotherapy for any malignant diseases, expected postoperative forced expiratory volume in 1.0 second $\geq 800 \mathrm{~mL}$ and arterial oxygen tension $\geq 65$ Torr. Sufficient organ function, and written informed consent were needed. Patients were excluded from the primary registration preoperatively if they met any of the following criteria: active bacterial or fungous infection present; simultaneous or metachronous (within the past 5 years) double cancers; women during pregnancy or breastfeeding; interstitial pneumonitis, pulmonary fibrosis, or severe pulmonary emphysema; psychosis; systemic steroidal medication; uncontrollable diabetes mellitus; uncontrollable hypertension; or a history of severe heart disease.

Intraoperative requirements for the secondary registration were surgery performed within 28 days of the primary registration, a histologically confirmed NSCLC, no malignant pleural effusion, no pleural dissemination, and no nodal involvement. Lesions should be technically resectable by lobectomy or segmentectomy with nodal dissection.

The study protocol was approved by the JCOG and WJOG Protocol Review Committees and the institutional review board of each participating hospital before initiation of the study. This study was conducted in accordance with the Declaration of Helsinki and the Japanese Ethical Guidelines for Clinical Research.

\section{Randomization and Masking}

Following confirmation of primary registration eligibility criteria, primary registration was made by telephone or fax to the JCOG Data Center from the institutions in JCOG or by fax to the WJOG Data Center from the institutions in WJOG. After confirming the eligibility criteria for the secondary registration, the registration was made by telephone to the JCOG Data Center from the institutions in the JCOG or WJOG Data Center and from the institutions in WJOG. Eligible patients were randomly allocated in a ratio of 1:1 to a lobectomy arm (Arm A) or segmentectomy arm (Arm B). Computer-generated randomization was done in each data center by a minimization method with a random component, balancing the arms by institution, histologic type (adenocarcinoma or others), sex, age ( $<70$ years or $\geq 70$ years) and thin-section CAT findings (solid or subsolid). Solid on thin-section CAT was defined as a tumor having no GGO. Patients and all investigators were unmasked to the treatment assignment.

\section{Procedures}

Surgery on participants in the trial was performed by general thoracic surgeons certified by the Japanese Association for Chest Surgery or equivalent as an operator or first assistant. Lobectomy in the trial included resection of the lobe other than middle lobe. Resection of more than 1 lobe was not permitted.

Segmentectomy was defined as resection of 1 segment or 1 segment and its additional adjacent segment; but basal segmentectomy was not regarded as segmentectomy. Surgical margin, the distance between the cut end uncovered by visceral pleura and the tumor margin, was evaluated macroscopically to confirm that the surgical margin was not less than the maximum tumor diameter or $20 \mathrm{~mm}$. Otherwise, frozen diagnosis or cytologic examination was mandatory for confirming tumor-free status on the cut end before closing the chest wall. Whenever the margin was positive for tumor cells, additional resection was mandatory. Segmentectomy was further categorized into simple or complex from the standpoint of technical aspect: resection of the right or left superior segment of the lower lobe

\section{Right lower lobectomy}

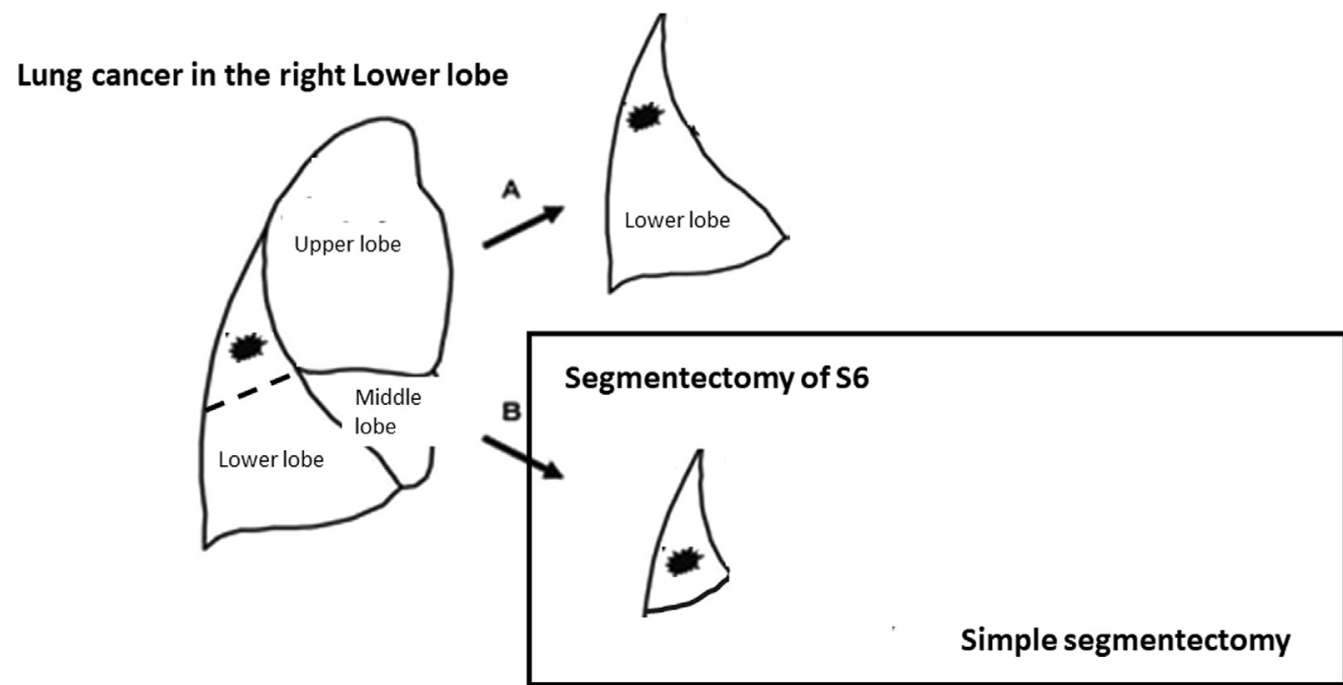

FIGURE 2. Scheme of resection of segment 6 in the right lower lobe, and this is categorized as simple segmentectomy. Simple segmentectomy was defined as resection of the right or left superior segment of the lower lobe (S6), the left superior, and the lingular segment. Resection of those segments is simple because there is just 1 intersegmental plane to identify. 


\section{Right Upper lobectomy}

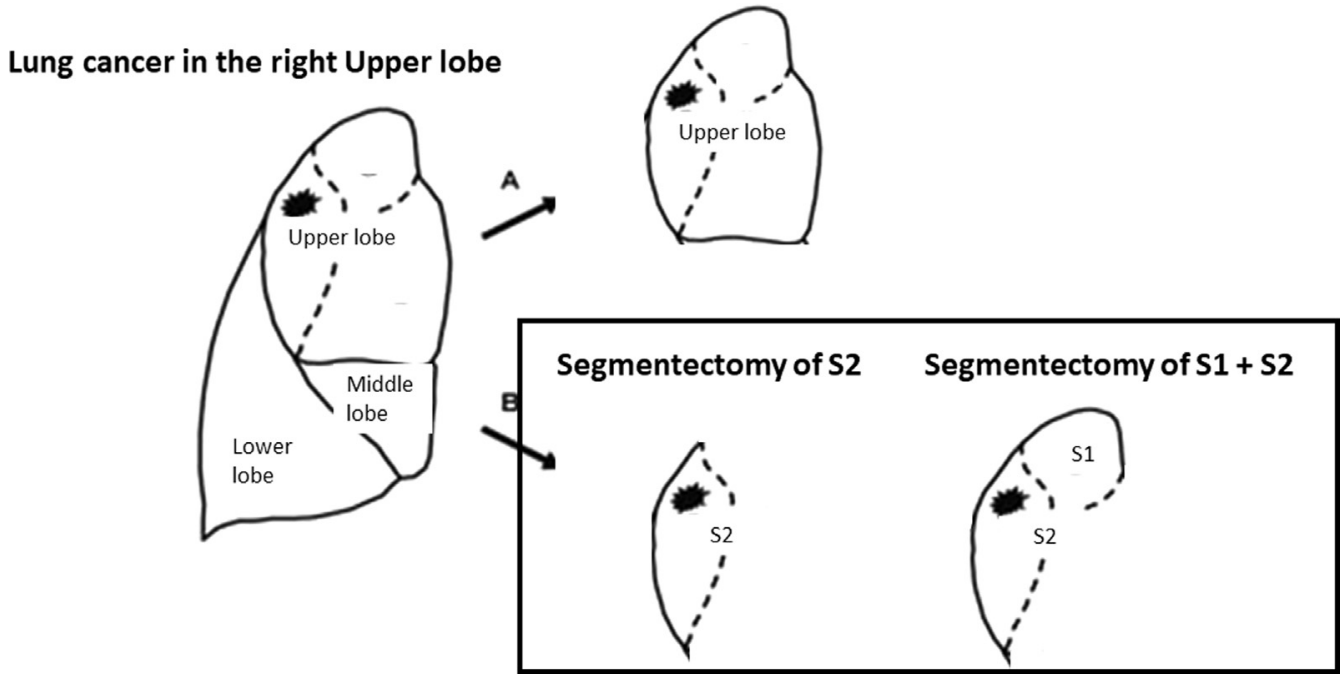

FIGURE 3. Scheme of resection of segment of $\mathrm{S} 2$ or bisegments of $\mathrm{S} 1$ and $\mathrm{S} 2$ in the right upper lobe, and both are categorized as complex segmentectomy. Complex segmentectomy was defined as resection of any segment other than bilateral superior segment of the lower lobe (S6), lingular, or superior segment of the left upper lobe. Moreover, complex segmentectomy was defined as resection of any segment that had more than 1 intersegmental plane.

(segment 6), the left superior, and the lingular segment was defined as simple (Figure 2). Complex segmentectomy was resection of segment other than that to be resected in the simple segmentectomy (Figure 3 and Video 1). Moreover, complex segmentectomy was defined as resection of a segment that had more than 1 intersegmental plane. As to segment 3 , there are 2 intersegmental planes. One is a plane between segment 1 and 3 , and the other is a plane between 2 and 3. Two or more intersegmental planes make segmentectomy more technically difficult even for certified thoracic surgeons. When a tumor located at the basal segment was difficult to remove by segmentectomy up to 2 segments, the mode of surgery was allowed be converted to basal segmentectomy or lobectomy because a combination of both was not regarded as the completion of segmentectomy.

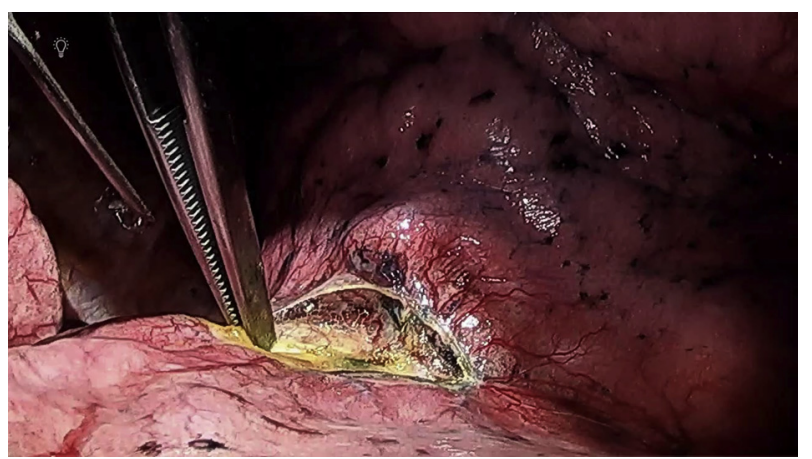

VIDEO 1. Segmentectomy was performed for lung cancer located in the posterior segment of the right upper lobe. Hilar dissection was performed to scarify ascending A2 and bronchus for segment 2. Following dissecting the hilar region, air was inflated through the distal bronchus of the segment 2 and inflation-deflation line was made. Stapling of the right upper lobe was done to complete segmentectomy. Operative time was 1 hour and $15 \mathrm{mi}-$ nutes and blood loss was $15 \mathrm{~mL}$. Complete resection and intraoperative confirmation of tumor free in the nodes were confirmed. Video available at: https://www.jtcvs.org/article/S0022-5223(19)30776-7/fulltext.
After the basal segmentectomy, an insufficient or presence of a positive surgical margin required pulmonary lobectomy for complete resection. When pure GGO was located in a different lobe, follow-up without resection was principally recommended; however, resection was also an option that was acceptable for the trial. Nodal dissection was mandatory for the hilar and mediastinal regions. Systematic dissection of mediastinal nodes was recommended, but selective dissection was also accepted. Selective nodal dissection is dissection of the superior mediastinal nodes for tumors located in the upper lobe, and inferior mediastinal nodes for those located in the lower lobe. Macroscopic swollen nodes were examined by frozen section diagnosis, and if found positive for tumor cells a change in surgical mode was required for complete resection. Sampling of the nodes was not acceptable.

To confirm that the randomized surgical procedures were performed properly, we reviewed the procedure centrally using photographs for all patients. The criterion for completion of protocol treatment was en bloc resection of the tumor.

All the randomized patients were followed for at least 5 years. Tumor markers and chest radiographs were evaluated at least every 6 months, and enhanced chest CAT scans were evaluated at least every 6 months during the first 2 years and at least every 12 months for the duration of the follow-up.

\section{Outcomes}

The primary end point of JCOG0802/WJOG4607L was OS in all randomized patients. The secondary end points were postoperative respiratory function, relapse-free survival, proportion of local recurrence, adverse events, proportion of completion of segmentectomy, length of hospital stay, duration of chest tube placement, operation time, blood loss, and number of auto staplers used. Of these, adverse events, proportion of completion of segmentectomy, blood loss, duration of chest tube placement, and number of auto staplers used are presented in this article. Postoperative early complication was defined as a complication occurring within 30 days from surgery. Complications were evaluated with the Common Terminology Criteria for Adverse Events version 3.0. With regard to postoperative fistula/pulmonary-lung (ie, air leak), during the chest drainage the following criteria were used: grade $0=$ none; grade $1=$ mild and no additional treatment required; grade $2=$ prolonged for more than 7 days 


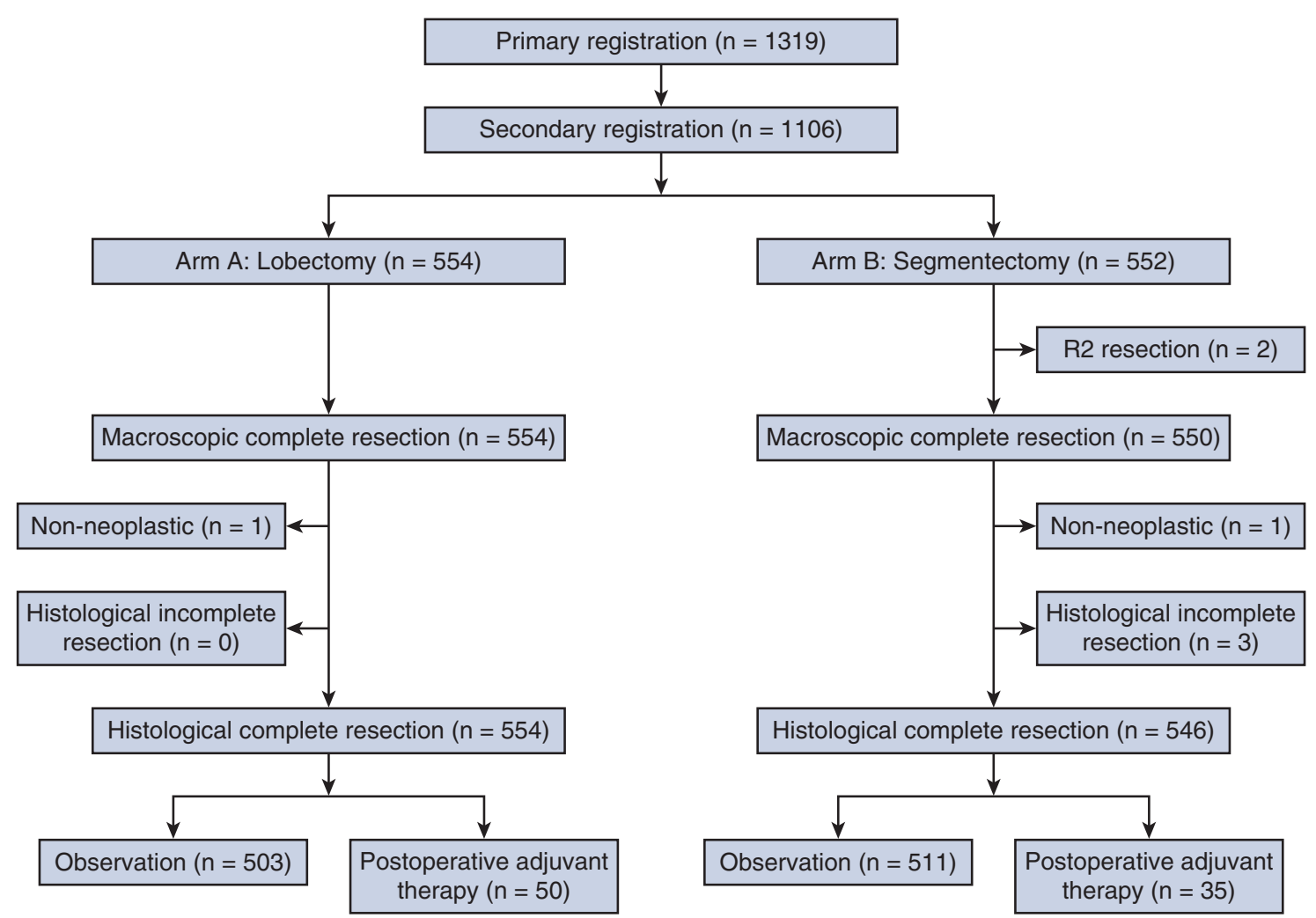

FIGURE 4. CONSORT diagram of the JCOG0802/WJOG4607L trial, which compared lobectomy and segmentectomy for the treatment of lung cancer with radiologically invasive appearance on thin-section computed tomography with stage I disease. Primary registration was done in 1319 patients and 1106 were randomized intraoperatively. Finally, 554 and 552 patients were randomized to lobectomy and segmentectomy arms, respectively.

after surgery or required pleural adhesion therapy; grade $3=$ reoperation required; and grade $4=$ life-threatening. Pulmonary complications were defined as fistula/pulmonary-lung (ie, air leak) and/or infection of the pleura (ie, empyema).

\section{Statistical Analysis}

The aim of this trial was to confirm the noninferiority of segmentectomy compared with lobectomy in OS. If the noninferiority of segmentectomy is confirmed and a superior postoperative pulmonary function of segmentectomy is observed, segmentectomy will be the preferred treatment for patients with peripheral NSCLC with diameter $\leq 2 \mathrm{~cm}$ and a $\mathrm{C} / \mathrm{T}$ ratio $\leq 0.5$. The planned sample size was 1100 patients to observe 131 events, with 550 patients per arm. We anticipated 5 years of follow-up after 3 years of accrual, ensuring at least $80 \%$ power with a 1 -sided $\alpha=5 \%$ and a noninferiority margin of $5 \%$ in terms of 5 -year OS for the primary end point. This assumed an expected 5-year OS of $90 \%$ in each arm.

Postoperative early complications were compared between the arms in intention-to-treat populations. Predictors for complications were investigated with the actual mode of surgery. Odds ratios (ORs) and their $95 \%$ confidence intervals (CIs) were estimated using logistic regression models for detecting predictors of postoperative complications and pulmonary complications. Multivariable logistic regression analyses that included mode of surgery, sex, age, maximum tumor diameter, pack-years of smoking, and location of tumor as covariates were performed. Pack-years of smoking was calculated using the following formula: smoking index per day $\times$ years of smoking. $P$ values were calculated using Wilcoxon ranksum test for the continuous variables, and Fisher exact test for the categorical variables. Ninety-five percent CIs of proportion of complications were estimated by the Clopper-Pearson method. All $P$ values were 2-sided. All statistical analyses were performed using SAS software, release 9.4 (SAS Institute Inc, Cary, NC).

\section{Role of the Funding Sources}

The funders had no role in the study design, data collection, data analysis, data interpretation, or writing of the report. The corresponding author (KS) had full access to all data in the study and had the final responsibility for deciding on the submission of the report for publication. This trial is registered with the University Hospital Medical Information NetworkClinical Trial Registry (No. UMIN000002317).

\section{RESULTS}

Between August 10, 2009, and October 21, 2014, there were 1319 primary registrations, of which 1106 patients (lobectomy $\mathrm{n}=554$, segmentectomy $\mathrm{n}=552$ ) were enrolled from 68 institutions $(\mathrm{JCOG} n=44$, WJOG $n=24)$. After the secondary registration, protocol treatment was completed in 553 patients in the lobectomy and 546 in the segmentectomy arms (Figure 4). In the segmentectomy arm, 22 patients were switched to lobectomy and 1 patient underwent wide wedge resection, which finally resulted in 576 lobectomies and 529 segmentectomies. With regard to the univariable analysis that included mode of surgery 
to investigate predictors for complications, 1 patient with wide wedge resection was removed from the analysis, resulting in a total of 1105 patients analyzed. With regard to the univariable analysis that included smoking status, smoking status was unclear for 4 patients, resulting in a total of 1102 patients for the univariable analysis using smoking status. With regard to the multivariable analysis, 5 patients -1 wedge resection and 4 with unclear pack-years of smoking-were excluded from the analysis, resulting in a total of 1101 cases.

The baseline characteristics of patients were well balanced in the 2 arms (Table 1). There were 583 (52.7\%) men and $523(47.3 \%)$ women who were randomized. The median age was 67 years with an interquartile range (IQR) of 61 to 72 years. Among 529 segmentectomies, the simple and complex forms were performed in 229 and 300 , respectively. C/T ratio $\leq 0.5$ was found in 63 and 73 patients in the lobectomy and segmentectomy arms, respectively. Between August 2009 and September 2013, the eligibility criterion of $\mathrm{C} / \mathrm{T}$ ratio $>0.25$ was changed to $>0.5$. Finally, lung cancers with $\mathrm{C} / \mathrm{T}$ ratio $>0.5$ were found in $970(87.7 \%)$, including $568(51.4 \%)$ tumors with $\mathrm{C} / \mathrm{T}$ ratio $=1$. The most common histologic typing was adenocarcinoma $(\mathrm{n}=968 ; 87.5 \%)$. Mediastinal nodal dissection was performed in 1079 (97.6\%). Macroscopic R0 resection was confirmed in $1104(99.8 \%)$ and $2(0.2 \%)$ R2 resections were noted in the segmentectomy arm. Histologic resection score showed $1099(99.4 \%)$ as R0, $3(0.3 \%)$ as R1, and 2 $(0.2 \%)$ as R2 (2 values were missing due to them being nonneoplastic).

Significantly more intraoperative blood loss was observed in the segmentectomy arm (lobectomy arm median, $44.5 \mathrm{~mL}$ [IQR, 20-95 mL] and segmentectomy arm median, $50 \mathrm{~mL}$ [IQR, 20-101 mL]; $P=.012$ ) (Table 2). The frequency of transfusion until the first morning after surgery was similar: $1(0.2 \%)$ in the lobectomy arm and 3 $(0.5 \%)$ in the segmentectomy arm $(P=.37)$. The median number of auto staplers used was 5 (IQR, 4-7) in both arms $(P=.43)$. Although median postoperative duration of the chest tube placement was identical (4 days) in both arms, the frequency of reinsertion of the chest drain was significantly higher in the segmentectomy arm $(P=.015): 8$ in the lobectomy arm $(1.4 \%)$ and 21 in the segmentectomy arm $(3.8 \%)$.

One or more intraoperative complications of grade $\geq 2$ occurred in 15 patients $(1.4 \%)$ : $6(1.1 \%)$ in the lobectomy arm, and $9(1.6 \%)$ in the segmentectomy arm (Table 3$)$. Occurrence of supraventricular arrhythmia grade $\geq 2$ was similar in both arms and ventricular extrasystole grade $\geq$ 2 was found only in the lobectomy arm. Injury of the pulmonary artery was seen in 7 patients in the lobectomy arm $(1.3 \%)$, and 2 patients in the segmentectomy arm $(0.4 \%)$; however, all were grade 1 except a single patient with grade 3. Bronchial injury occurred in 1 patient in the lobectomy
TABLE 1. Patient characteristics at registration

\begin{tabular}{|c|c|c|}
\hline Characteristic & $\begin{array}{c}\text { Lobectomy } \\
\text { group } \\
(\mathbf{n}=\mathbf{5 5 4}) \\
\end{array}$ & $\begin{array}{c}\text { Segmentectomy } \\
\text { group } \\
(\mathbf{n}=\mathbf{5 5 2})^{*} \\
\end{array}$ \\
\hline \multicolumn{3}{|l|}{ Age (y) } \\
\hline Median & 67 & 67 \\
\hline Interquartile range & $61-72$ & $61-72$ \\
\hline Range & $35-85$ & $32-83$ \\
\hline \multicolumn{3}{|l|}{ Sex } \\
\hline Women & $261(47.1)$ & $262(47.5)$ \\
\hline Men & $293(52.9)$ & $290(52.5)$ \\
\hline \multicolumn{3}{|l|}{ Location of tumor } \\
\hline Right upper lobe & $160(28.9)$ & $167(30.3)$ \\
\hline Right lower lobe & $143(25.8)$ & $117(21.2)$ \\
\hline Left upper lobe & $163(29.4)$ & $187(33.9)$ \\
\hline Left lower lobe & $88(15.9)$ & $81(14.7)$ \\
\hline \multicolumn{3}{|c|}{$\begin{array}{l}\text { Preoperative maximum tumor } \\
\text { diameter on lung view on thin- } \\
\text { section computed tomography } \\
\text { (cm) }\end{array}$} \\
\hline Median & 1.60 & 1.585 \\
\hline Interquartile range & $1.30-1.80$ & $1.30-1.80$ \\
\hline Range & $0.60-2.00$ & $0.60-2.00$ \\
\hline \multicolumn{3}{|c|}{$\begin{array}{l}\text { Preoperative maximum consolidation } \\
\text { dimension on lung view on thin- } \\
\text { section computed tomography } \\
\text { (cm) }\end{array}$} \\
\hline Median & 1.24 & 1.265 \\
\hline Interquartile range & $0.95-1.60$ & $0.91-1.60$ \\
\hline Range & $0.29-2.00$ & $0.31-2.00$ \\
\hline \multicolumn{3}{|l|}{ Consolidation tumor ratio } \\
\hline 0 to $\leq 0.25$ & $1(0.2)$ & $0(0)$ \\
\hline 0.25 to $\leq 0.5$ & $62(11.2)$ & $73(13.2)$ \\
\hline 0.5 to $<1$ & $208(37.6)$ & $194(35.1)$ \\
\hline 1 & $283(51.1)$ & $285(51.6)$ \\
\hline \multicolumn{3}{|c|}{ Forced expiratory volume in $1.0 \mathrm{~s}(\mathrm{~mL})$} \\
\hline Median & 2260 & 2280 \\
\hline Interquartile range & $1870-2690$ & $1960-2725$ \\
\hline Range & $1110-4760$ & $1010-4900$ \\
\hline \multicolumn{3}{|l|}{ Forced vital capacity $(\mathrm{mL})$} \\
\hline Median & 3050 & 3095 \\
\hline Interquartile range & $2530-3640$ & $2610-3680$ \\
\hline Range & $1370-5990$ & $1590-5940$ \\
\hline \multicolumn{3}{|c|}{ Histologic diagnosis on registration } \\
\hline Squamous cell carcinoma & $35(6.3)$ & $38(6.9)$ \\
\hline Adenocarcinoma & $485(87.5)$ & $483(87.5)$ \\
\hline Large cell carcinoma & $0(0)$ & $1(0.2)$ \\
\hline Adenosquamous carcinoma & $3(0.5)$ & $0(0)$ \\
\hline Non-small carcinoma & $31(5.6)$ & $30(5.4)$ \\
\hline
\end{tabular}

Values are presented as $\mathrm{n}(\%)$ unless otherwise noted. *Segmentectomy group includes 1 wide wedge resection and 22 lobectomies that were converted from segmentectomy

arm $(0.2 \%)$, and 6 in the segmentectomy arm $(1.1 \%)$. Onset of organ injury was similar in both arms. With regard to the sensitivity analysis, 1 or more intraoperative 
TABLE 2. Factors related to surgery and pathology

\begin{tabular}{|c|c|c|c|}
\hline Factor & $\begin{array}{l}\text { Lobectomy group } \\
\quad(\mathbf{n}=\mathbf{5 5 4})\end{array}$ & $\begin{array}{l}\text { Segmentectomy group } \\
(\mathbf{n}=\mathbf{5 5 2})^{*}\end{array}$ & $\begin{array}{r}\text { 2-Sided } \\
P \text { value } \dagger\end{array}$ \\
\hline \multicolumn{4}{|l|}{ Histologic diagnosis on surgical specimen } \\
\hline Squamous cell carcinoma & $38(6.9)$ & $37(6.7)$ & \\
\hline Adenocarcinoma & $501(90.4)$ & $502(90.9)$ & \\
\hline Others & $15(2.7)$ & $13(2.4)$ & \\
\hline \multicolumn{4}{|l|}{ Nodal dissection } \\
\hline No dissection & $0(0)$ & $1(0.2)$ & \\
\hline Hilar & $9(1.6)$ & $17(3.1)$ & \\
\hline Mediastinal & $544(98.2)$ & $534(96.7)$ & \\
\hline Systematic & $325(58.7)$ & $352(63.8)$ & \\
\hline Selective & $220(39.7)$ & $182(33.0)$ & \\
\hline \multicolumn{4}{|l|}{ Macroscopic resection score } \\
\hline R0 & $554(100)$ & $550(99.6)$ & \\
\hline $\mathrm{R} 1$ & $0(0)$ & $0(0)$ & \\
\hline $\mathrm{R} 2$ & $0(0)$ & $2(0.4)$ & \\
\hline $\mathrm{RX}$ & $0(0)$ & $0(0)$ & \\
\hline \multicolumn{4}{|l|}{ Histologic resection score } \\
\hline R0 & $553(99.8)$ & $546(98.9)$ & \\
\hline $\mathrm{R} 1$ & $0(0)$ & $3(0.5)$ & \\
\hline $\mathrm{R} 2$ & $0(0)$ & $2(0.4)$ & \\
\hline $\mathrm{RX}$ & $0(0)$ & $0(0)$ & \\
\hline Missing data & $1(0.2)$ & $1(0.2)$ & \\
\hline \multicolumn{4}{|l|}{ Intraoperative blood loss (mL) } \\
\hline Median & 44.5 & 50 & \\
\hline Interquartile range & $20-95$ & $20-101$ & \\
\hline Range & $0-900$ & $0-800$ & .012 \\
\hline \multicolumn{4}{|c|}{$\begin{array}{l}\text { Transfusion of packed red blood cell since operation to the morning of the } \\
\text { first postoperative day }\end{array}$} \\
\hline None & $553(99.8)$ & $549(99.5)$ & \\
\hline Done & $1(0.2)$ & $3(0.5)$ & .37 \\
\hline Median (unit) & 4 & 2 & \\
\hline Interquartile range & $4-4$ & $2-2$ & \\
\hline Range & $4-4$ & $2-2$ & .25 \\
\hline \multicolumn{4}{|l|}{ Number of used auto staplers used } \\
\hline Median & 5 & 5 & \\
\hline Interquartile range & $4-7$ & $4-7$ & \\
\hline Range & $1-15$ & $0-15$ & .43 \\
\hline \multicolumn{4}{|l|}{ The duration of chest tube placement (d) } \\
\hline Median & 4 & 4 & \\
\hline Interquartile range & $3-5$ & $3-5$ & \\
\hline Range & $1-29$ & $2-35$ & .62 \\
\hline \multicolumn{4}{|l|}{ Reinsertion of chest drain } \\
\hline None & $546(98.6)$ & $531(96.2)$ & \\
\hline Yes & $8(1.4)$ & $21(3.8)$ & .015 \\
\hline
\end{tabular}

Values are presented as $\mathrm{n}(\%)$ unless otherwise noted. *Segmentectomy group includes 1 wide wedge resection and 22 lobectomies that were converted from segmentectomy. $\dagger$ Calculated with Wilcoxon rank-sum test for continuous variables, and with Fisher exact test for categorical variables.

complications of grade $\geq 2$ occurred in 7 out of 576 lobectomies $(1.2 \%)$, and 8 out of 529 segmentectomies $(1.5 \%)$, and the number was similar to that shown in the intentionto-treat analysis.

Neither 30-day nor 90-day mortality was observed. One or more early postoperative complications grade $\geq 2$ occurred at a similar frequency in both arms $(P=.68)$ (Table 4): 142 patients (25.6\%) in the lobectomy arm, and 148 patients $(26.8 \%)$ in the segmentectomy arm. Reoperation was performed in 11 of 554 patients $(2.0 \%)$ in the lobectomy arm and 6 of 552 patients $(1.1 \%)$ in the segmentectomy arm $(P=.33)$ (Table 5). Three patients underwent 
TABLE 3. Intraoperative complications by intent to treat analyses

\begin{tabular}{|c|c|c|c|c|c|c|c|c|}
\hline \multirow[b]{3}{*}{ Complication } & \multicolumn{4}{|c|}{ Lobectomy group $(n=554)$} & \multicolumn{4}{|c|}{ Segmentectomy group $(n=552)$} \\
\hline & \multicolumn{8}{|c|}{ CTCAE grade } \\
\hline & 1 & 2 & 3 & 4 & 1 & 2 & 3 & 4 \\
\hline \multicolumn{9}{|l|}{ Supraventricular arrhythmia } \\
\hline Atrial fibrillation & 2 & 0 & 0 & 0 & 3 & 3 & 0 & 0 \\
\hline Atrial flutter & 1 & 0 & 0 & 0 & 0 & 0 & 0 & 0 \\
\hline $\begin{array}{l}\text { Atrial tachycardia/paroxysmal } \\
\text { atrial tachycardia }\end{array}$ & 2 & 0 & 1 & 0 & 1 & 0 & 1 & 0 \\
\hline Sinus bradycardia & 2 & 1 & 0 & 0 & 1 & 0 & 0 & 0 \\
\hline Any supraventricular arrhythmia & 5 & 1 & 1 & 0 & 5 & 3 & 1 & 0 \\
\hline \multicolumn{9}{|l|}{ Ventricular arrhythmia } \\
\hline Premature ventricular contraction & 5 & 2 & 1 & 0 & 0 & 0 & 0 & 0 \\
\hline Any arrhythmia & 9 & 3 & 1 & 0 & 5 & 3 & 1 & 0 \\
\hline Cardiac ischemia/infarction & 0 & 0 & 0 & 0 & 0 & 0 & 0 & 0 \\
\hline \multicolumn{9}{|l|}{ Organ injury } \\
\hline Artery, aorta & 0 & 0 & 0 & 0 & 0 & 0 & 0 & 0 \\
\hline Artery, pulmonary & 7 & 0 & 0 & 0 & 1 & 0 & 1 & 0 \\
\hline Heart & 0 & 0 & 0 & 0 & 0 & 0 & 0 & 0 \\
\hline Inferior vena cave & 0 & 0 & 0 & 0 & 0 & 0 & 0 & 0 \\
\hline Vein, pulmonary & 0 & 0 & 0 & 0 & 1 & 0 & 0 & 0 \\
\hline Vein, superior vena cava & 0 & 0 & 0 & 0 & 0 & 0 & 0 & 0 \\
\hline Trachea & 0 & 0 & 0 & 0 & 0 & 0 & 0 & 0 \\
\hline Lung & 11 & 1 & 0 & 0 & 8 & 2 & 0 & 0 \\
\hline Bronchus & 1 & 0 & 0 & 0 & 5 & 1 & 0 & 0 \\
\hline Mediastinum & 0 & 0 & 0 & 0 & 0 & 0 & 0 & 0 \\
\hline Pleura & 0 & 0 & 0 & 0 & 0 & 0 & 0 & 0 \\
\hline Thoracic duct & 0 & 0 & 0 & 0 & 0 & 0 & 0 & 0 \\
\hline Any organ injury & 19 & 1 & 0 & 0 & 14 & 2 & 1 & 0 \\
\hline Any intraoperative complication & 28 & 5 & 1 & 0 & 10 & 7 & 2 & 0 \\
\hline
\end{tabular}

CTCAE, Common Terminology Criteria for Adverse Events version 3.0.

reoperation due to positive or insufficient surgical margin. One was positive surgical margin due to micropapillary extension of the tumor, the other 2 were negative but insufficient surgical margin (ie, $<2 \mathrm{~cm}$ ) based on permanent pathologic diagnosis.

With regard to postoperative cardiac arrhythmias, atrial fibrillation grade $\geq 2$ occurred at a similar rate in both $\operatorname{arms}(P=.88): 22$ in the lobectomy arm $(4.0 \%)$ and 20 in the segmentectomy arm $(3.6 \%)$. Postoperative pneumonia grade $\geq 2$ with normal absolute neutrophil count occurred at a similar rate in both arms $(P=.18): 4$ in the lobectomy $\operatorname{arm}(0.7 \%)$ and 9 in the segmentectomy arm $(1.6 \%)$. Pneumonias with abnormal absolute neutrophil count were not observed. The frequency of fistula/pulmonary-lung (ie, air leak) grade $\geq 2$ was significantly higher in the segmentectomy arm $(P=.042): 21$ in the lobectomy arm $(3.8 \%)$ and 36 in the segmentectomy arm $(6.5 \%)$. Twenty-three complex and 11 simple segmentectomies were performed in patients with air leak grade $\geq 2$. With regard to lobectomy, there were 10 right upper, 5 right lower, 7 left upper, and 1 left lower lobe, which had postoperative fistula/ pulmonary-lung (ie, air leak) grade $\geq 2$. There was no bronchopleural fistula in either arm. Central nervous system ischemia was noted as grade 4 in both arms with similar incidence: 2 in the lobectomy arm and 1 in the segmentectomy arm. As for pulmonary embolism, which is among the most lethal complications after major pulmonary resection, this was found in 0 and 3 ( 2 grade 3 , and 1 grade 4 ) patients in the lobectomy and segmentectomy arms, respectively. Atelectasis, chylothorax, recurrent laryngeal nerve palsy, and phrenic nerve dysfunction occurred at similar frequencies in both arms. With regard to sensitivity analysis, $\geq 1$ postoperative complications of grade $\geq 2$ occurred in $152(26.4 \%)$ out of 576 lobectomies, and $138(26.1 \%)$ out of 529 segmentectomies, and the numbers were similar to those in the intention-to-treat analysis.

Univariable logistic regression analysis revealed predictors of postoperative complications grade $\geq 2$ to be sex (women vs men OR, $0.75 ; 95 \%$ CI, 0.57-0.99) and smoking (pack-years of smoking $<20$ vs none OR, $1.31 ; 95 \% \mathrm{CI}$, 
TABLE 4. Postoperative early complications by intention-to-treat analyses

\begin{tabular}{|c|c|c|c|c|c|c|c|c|}
\hline \multirow[b]{3}{*}{ Complication } & \multicolumn{4}{|c|}{ Lobectomy group $(n=554)$} & \multicolumn{4}{|c|}{ Segmentectomy group $(n=552)$} \\
\hline & \multicolumn{8}{|c|}{ CTCAE grade } \\
\hline & 1 & 2 & 3 & 4 & 1 & 2 & 3 & 4 \\
\hline \multicolumn{9}{|l|}{ Supraventricular arrhythmia } \\
\hline Atrial fibrillation & 6 & 21 & 1 & 0 & 0 & 19 & 1 & 0 \\
\hline Atrial tachycardia/paroxysmal atrial tachycardia & 1 & 7 & 0 & 0 & 0 & 7 & 1 & 0 \\
\hline Any supraventricular arrhythmia & 6 & 24 & 1 & 0 & 0 & 26 & 2 & 0 \\
\hline Fever & 50 & 7 & 0 & 0 & 72 & 1 & 0 & 0 \\
\hline \multicolumn{9}{|l|}{ Infection with normal ANC } \\
\hline Lung & - & 0 & 4 & 0 & - & 2 & 7 & 0 \\
\hline Pleura, empyema & - & 0 & 3 & 0 & - & 1 & 5 & 0 \\
\hline \multicolumn{9}{|l|}{ Fistula/pulmonary } \\
\hline Lung & 16 & 18 & 3 & 0 & 16 & 35 & 1 & 0 \\
\hline Bronchus & 0 & 0 & 0 & 0 & 0 & 0 & 0 & 0 \\
\hline Atelectasis & 10 & 4 & 0 & 0 & 16 & 4 & 0 & 0 \\
\hline Chylothorax & 5 & 9 & 5 & 0 & 4 & 6 & 0 & 0 \\
\hline Cough & 50 & 5 & 0 & - & 45 & 10 & 0 & - \\
\hline Pneumonitis & 1 & 0 & 0 & 0 & 0 & 1 & 0 & 0 \\
\hline Pain chest/thorax, NOS & 79 & 53 & 2 & 0 & 84 & 51 & 2 & 0 \\
\hline CNS ischemia & - & 0 & 0 & 2 & - & 0 & 0 & 1 \\
\hline Recurrent laryngeal nerve palsy & 2 & 10 & 0 & 0 & 1 & 8 & 0 & 0 \\
\hline Phrenic nerve dysfunction & 0 & 1 & 0 & 0 & 2 & 0 & 0 & 0 \\
\hline Thrombosis/thrombus/embolism & 0 & 0 & 0 & 0 & 0 & 0 & 2 & 1 \\
\hline Any early postoperative complication & 120 & 115 & 24 & 3 & 132 & 123 & 23 & 2 \\
\hline
\end{tabular}

CTCAE, Common Terminology Criteria for Adverse Events version 3.0; ANC, absolute neutrophil count; NOS, not otherwise specified; CNS, central nervous system.

0.83-2.06; pack-years of smoking $\geq 20$ vs none OR, 1.53; 95\% CI, 1.15-2.04) (Table 6). Multivariable logistic regression analysis that included all covariates revealed packyears of smoking $\geq 20$ versus none OR, $1.54 ; 95 \% \mathrm{CI}$, 1.03-2.29 $(P=.035)$ to be a significant predictor. Predictors of pulmonary complications, including air leakage and empyema (grade $\geq 2$ ) based on a univariable logistic regression analysis were sex (women OR, 0.37; 95\% CI, 0.21$0.66 ; P<.001$ ), pack-years of smoking $\geq 20$ (OR, 3.44; $95 \%$ CI, 1.82-6.49; $P<.001)$, complex segmentectomy (OR, 1.83; 95\% CI, 1.02-3.28; $P=.043)$ and left lower lobectomy (OR, $0.25 ; 95 \%$ CI, $0.07-0.85 ; P=.026$ ) (Table 7). Multivariable analysis revealed the following predictors of pulmonary complication: complex segmentectomy (OR, 2.07; 95\% CI, 1.11-3.88; $P=.023)$ and packyears of smoking $\geq 20$ (OR, 2.61; 95\% CI, 1.14-5.97; $P=.023$ ). No predictors of postoperative supraventricular arrhythmia were detected.

\section{DISCUSSION}

In this study, segmentectomy, including complex procedures, showed feasible morbidity and mortality compared with lobectomy for patients with small-sized peripheral
NSCLC. However, segmentectomy was associated with higher chance of air leak and intraoperative blood loss (although not clinically significant).

Segmentectomy is fundamentally a more limited parenchymal resection and is being advocated for early lung cancer. The advantages of segmentectomy could be preservation of lung function, low frequency of surgical morbidity and mortality, less intraoperative blood loss, shorter hospital stay, and so on; however, those have never been investigated based on data from a randomized trial except 1 reported by LCSG in $1995 .{ }^{5}$ Although this LCSG trial concluded that lobectomy was a standard for lung cancer operation, it included 40 wedge resections in the sublobar arm $(n=122)$ and that was among the reasons why lobectomy was preferred over sublobar resection in this trial. Thus, the LCSG trial was the first randomized comparison between lobectomy and segmentectomy for resectable lung cancer. In this context, we conducted a phase III trial to evaluate the noninferiority in OS of segmentectomy compared with lobectomy in patients with small-sized peripheral NSCLC.

Segmentectomy was associated with higher chance of air leak. Generally speaking, segmentectomy is more 
TABLE 5. Reoperation details

\begin{tabular}{|c|c|c|c|}
\hline Cause & $\begin{array}{l}\text { Lobectomy group } \\
\quad(\mathbf{n}=\mathbf{5 5 4})\end{array}$ & $\begin{array}{c}\text { Segmentectomy } \\
\text { group } \\
(\mathbf{n}=\mathbf{5 5 2})\end{array}$ & $\begin{array}{c}\text { 2-Sided } \\
P \text { value* }\end{array}$ \\
\hline Lung abscess & 1 & 0 & \\
\hline Cardiac tamponade & 1 & 0 & \\
\hline Chylothorax & 5 & 0 & \\
\hline Bleeding & 2 & 2 & \\
\hline Lung fistula & 2 & 1 & \\
\hline $\begin{array}{c}\text { Positive/insufficient } \\
\text { surgical margin }\end{array}$ & 0 & $3 \dagger$ & \\
\hline Total reoperations & $11(2.0)$ & $6(1.1)$ & .33 \\
\hline \multicolumn{4}{|c|}{$\begin{array}{l}\text { Values are presented as } \mathrm{n} \text { or } \mathrm{n}(\%) . C I \text {, Confidence interval. }{ }^{*} \text { Calculated with Wil- } \\
\text { coxon rank-sum test for continuous variables, and with Fisher exact test for categor- } \\
\text { ical variables. } \dagger \text { One was positive surgical margin due to micropapillary extension of } \\
\text { the tumor, the other } 2 \text { were negative but insufficient surgical margin, }<2 \mathrm{~cm} \text {, based on } \\
\text { permanent pathologic diagnosis. }\end{array}$} \\
\hline
\end{tabular}

technically demanding for thoracic surgeons. We had 552 patients in segmentectomy arm and 22 segmentectomies were converted to lobectomy and 1 finished in wide wedge resection, resulting in 529 segmentectomies in this study. Before fixing the JCOG0802/WJOG4607L study protocol, we seriously discussed whether or not all kinds of segmentectomy should be eligible. Most thoracic surgeons are familiar with segmentectomy, but the familiar segmentectomy would be simple; that is, resection of right or left superior segment of the lower lobe (segment 6), superior division of the left upper lobe, or lingular of the left upper lobe. Few thoracic surgeons are familiar with resection of segment 1 in the right upper lobe, or segment 9 in the lower lobe, for instance. Finally, we decided to include all kinds of segmentectomy in the JCOG0802/ WJOG4607L trial. Among the most striking differences between simple and complex segmentectomy is the way of creating fissure. For instance, most complex segmentectomy cannot be performed with a stapler for creating fissure. Electrocautery must be used for creating fissure instead. On the other hand, simple segmentectomy can be performed with a stapler for creating fissure, which is due to just 1 intersegmental plane. To accomplish resection of segment 9 in the lower lobe, thoracic surgeons should create 4 intersegmental fissures, and this is not an easy task even for certified surgeons. Therefore, we defined simple and complex segmentectomy as a post-hoc definition, and retrospectively investigated the relationship among those procedures and postoperative complications. Unexpectedly complex segmentectomy was more than simple in number in this trial. Creating fissure with cautery should be more demanding than with stapler, and postoperative air leakage was more often observed in segmentectomy arm. This is supported by results from the multivariate analysis for predicting

TABLE 6. Predictors of early postoperative complication of grade 2 or more

\begin{tabular}{|c|c|c|c|c|c|c|}
\hline \multirow[b]{2}{*}{ Predictor } & \multirow{2}{*}{$\begin{array}{c}\text { Number per } \\
\text { event/total }\end{array}$} & \multirow[b]{2}{*}{$\%(95 \%$ CI $)$} & \multicolumn{2}{|l|}{ Univariable } & \multicolumn{2}{|c|}{ Multivariable* } \\
\hline & & & $\overline{\text { Odds ratio }(95 \% \text { CI })}$ & $P$ value & $\overline{\text { Odds ratio }(95 \% \mathrm{CI})}$ & $P$ value \\
\hline \multicolumn{7}{|l|}{ Mode of surgery } \\
\hline Lobectomy & $152 / 576$ & $26.4(22.8-30.2)$ & 1 & $.90 \dagger$ & 1 & $.89 \dagger$ \\
\hline Complex & $76 / 300$ & $25.3(20.5-30.7)$ & $0.95(0.69-1.30)$ & .74 & $1.05(0.75-1.46)$ & .79 \\
\hline Simple & $62 / 229$ & $27.1(21.4-33.3)$ & $1.04(0.73-1.46)$ & .84 & $0.94(0.65-1.36)$ & .74 \\
\hline \multicolumn{7}{|l|}{$\operatorname{Sex}$} \\
\hline Men & $168 / 583$ & $28.8(25.2-32.7)$ & 1 & .039 & 1 & .94 \\
\hline Women & $122 / 523$ & $23.3(19.8-27.2)$ & $0.75(0.57-0.99)$ & & $0.99(0.68-1.43)$ & \\
\hline \multicolumn{7}{|c|}{ Age at secondary registration (y) } \\
\hline$<75$ & $250 / 971$ & $25.8(23.0-28.6)$ & 1 & .34 & 1 & .28 \\
\hline$>76$ & $40 / 135$ & $29.6(22.1-38.1)$ & $1.21(0.82-1.81)$ & & $1.25(0.84-1.87)$ & \\
\hline \multicolumn{7}{|c|}{ Maximum tumor diameter $(\mathrm{cm})$} \\
\hline$\leq 1.5$ & $128 / 517$ & $24.8(21.1-28.7)$ & 1 & .30 & 1 & .46 \\
\hline$>1.5$ & $162 / 589$ & $27.5(23.9-31.3)$ & $1.15(0.88-1.51)$ & & $1.11(0.84-1.46)$ & \\
\hline \multicolumn{7}{|l|}{ Pack-years smoking } \\
\hline None & $108 / 490$ & $22.0(18.4-26.0)$ & 1 & $.015 \dagger$ & 1 & $.11 \dagger$ \\
\hline$<20$ & $33 / 122$ & $27.1(19.4-35.8)$ & $1.31(0.83-2.06)$ & .24 & $1.28(0.79-2.09)$ & .32 \\
\hline$\geq \mathbf{2 0}$ & $148 / 490$ & $30.2(26.2-34.5)$ & $1.53(1.15-2.04)$ & .004 & $1.54(1.03-2.29)$ & .035 \\
\hline \multicolumn{7}{|l|}{ Location of tumor } \\
\hline Right upper lobe & $77 / 327$ & $23.6(19.1-28.5)$ & 1 & $.21 \dagger$ & 1 & $.21 \dagger$ \\
\hline Right lower lobe & $72 / 260$ & $27.7(22.3-33.6)$ & $1.24(0.86-1.81)$ & .25 & $1.33(0.90-1.97)$ & .15 \\
\hline Left upper lobe & $103 / 350$ & $29.4(24.7-34.5)$ & $1.35(0.96-1.91)$ & .084 & $1.43(0.97-2.11)$ & .071 \\
\hline Left lower lobe & $38 / 169$ & $22.5(16.4-29.5)$ & $0.94(0.61-1.47)$ & .79 & $1.02(0.65-1.62)$ & .92 \\
\hline
\end{tabular}

Boldface indicates significant parameters. $C I$, Confidence interval. *Including all variables. $\dagger$ Total. 
TABLE 7. Predictors of early postoperative pulmonary complications of grade 2 or more*

\begin{tabular}{|c|c|c|c|c|c|c|}
\hline \multirow[b]{2}{*}{ Predictor } & \multirow{2}{*}{$\begin{array}{l}\text { Number per } \\
\text { event/total }\end{array}$} & \multirow[b]{2}{*}{$\%(95 \%$ CI $)$} & \multicolumn{2}{|c|}{ Univariable } & \multicolumn{2}{|c|}{ Multivariable $\dagger$} \\
\hline & & & Odds ratio $(95 \% \mathrm{CI})$ & $P$ value & Odds ratio $(95 \% \mathrm{CI})$ & $P$ value \\
\hline \multicolumn{7}{|l|}{ Mode of surgery } \\
\hline Lobectomy & $25 / 576$ & $4.3(2.8-6.3)$ & 1 & $.12 \ddagger$ & 1 & $.069 \ddagger$ \\
\hline Complex & $23 / 300$ & $7.7(4.9-11.3)$ & $1.83(1.02-3.28)$ & .043 & $2.07(1.11-3.88)$ & .023 \\
\hline Simple & $14 / 229$ & $6.1(3.4-10.0)$ & $1.44(0.73-2.81)$ & .29 & $1.47(0.71-3.05)$ & .30 \\
\hline \multicolumn{7}{|l|}{ Sex } \\
\hline Men & $46 / 583$ & $7.9(5.8-10.4)$ & 1 & .0008 & 1 & .30 \\
\hline Women & $16 / 523$ & $3.1(1.8-4.9)$ & $0.37(0.21-0.66)$ & & $0.67(0.31-1.43)$ & \\
\hline \multicolumn{7}{|c|}{ Age at secondary registration $(\mathrm{y})$} \\
\hline$\leq 75$ & $54 / 971$ & $5.6(4.2-7.2)$ & 1 & .86 & 1 & .74 \\
\hline$\geq 76$ & $8 / 135$ & $5.9(2.6-11.3)$ & $1.07(0.50-2.30)$ & & $1.14(0.52-2.50)$ & \\
\hline \multicolumn{7}{|c|}{ Maximum tumor diameter $(\mathrm{cm})$} \\
\hline$\leq 1.5$ & $25 / 517$ & $4.8(3.2-7.1)$ & 1 & .30 & 1 & .29 \\
\hline$>1.5$ & $37 / 589$ & $6.3(4.5-8.6)$ & $1.32(0.78-2.22)$ & & $1.34(0.78-2.30)$ & \\
\hline \multicolumn{7}{|l|}{ Pack-years of smoking } \\
\hline None & $13 / 490$ & $2.7(1.4-4.5)$ & 1 & .0006 & 1 & $.061 \ddagger$ \\
\hline$<20$ & $6 / 122$ & $4.9(1.8-10.4)$ & $1.90(0.71-5.10)$ & .20 & $1.52(0.52-4.38)$ & .44 \\
\hline$\geq \mathbf{2 0}$ & $42 / 490$ & $8.6(6.2-11.4)$ & $3.44(1.82-6.49)$ & .0001 & $2.61(1.14-5.97)$ & .023 \\
\hline \multicolumn{7}{|l|}{ Location of tumor } \\
\hline Right upper lobe & $22 / 327$ & $6.7(4.3-10.0)$ & 1 & $.17 \ddagger$ & 1 & $.21 \ddagger$ \\
\hline Right lower lobe & $16 / 260$ & $6.2(3.6-9.8)$ & $0.91(0.47-1.77)$ & .78 & $1.23(0.60-2.54)$ & .57 \\
\hline Left upper lobe & $21 / 350$ & $6.0(3.8-9.0)$ & $0.89(0.48-1.64)$ & .70 & $1.04(0.50-2.17)$ & .93 \\
\hline Left lower lobe & $3 / 169$ & $1.8(0.4-5.1)$ & $0.25(0.07-0.85)$ & .026 & $0.32(0.09-1.09)$ & .069 \\
\hline
\end{tabular}

Boldface indicates significant parameters. $C I$, Confidence interval. *Pulmonary complications were defined as fistula of lung or infection of the pleura; that is, empyema. $\dagger$ Including all variables. †TTotal.

pulmonary complications. A surgeon creates fissure with just cautery, with just stapler, or with stapler and cautery, and we had no accurate number of each method in JCOG0802. Creating fissure might relate to postoperative complications, especially prolonged air leakage. Whether this technical difficulty relates to local failure and/or survival will be investigated in the final analysis. Some of the other secondary end points in the trial were also evaluated in this study; namely, proportion of completion of segmentectomy, blood loss, duration of chest tube placement, and number of autostaplers. Segmentectomy as defined in this trial was actually completed on 526 out of 552 patients $(95.3 \%)$ allocated to the segmentectomy arm in the secondary registration; segmentectomy was switched to lobectomy in 22 patients and wedge resection was performed in 1 patient. The protocol requirement of $\geq 90 \%$ completed segmentectomies was met, and as such, we considered our strategy of adopting segmentectomy for this population to be feasible. Intraoperative blood loss was more significant in the segmentectomy arm than the lobectomy arm, although the difference was a median of $5.5 \mathrm{~mL}$ and was not clinically significant. The frequencies of transfusion until the next morning after the operation were similar at $<1 \%$. The duration of chest tube placement was identical in both arms; however, reinsertion of the chest drain took longer in the segmentectomy arm due mostly to delayed air leakage. Theoretically, segmentectomy would need more staplers than lobectomy; however, the number of autostaplers used was identical in both arms. The median number of auto staplers used was 5 in both study arms, which matches the allowed number of 6 staplers for thoracic surgeons in lung cancer surgery by the Japanese national insurance system. Taking those things into consideration, segmentectomy was more technically demanding compared with lobectomy from the viewpoints of these secondary end points. Video-assisted procedures were done in 491 $(88.7 \%)$ and $495(89.7 \%)$ patients in the lobectomy and segmentectomy arms, respectively. However, our definition of video-assisted procedure was not rigid and video-assisted minithoracotomy was categorized as a video-assisted procedure. The accurate number of cases performed by 3- or 4-port procedure was unknown. Thus, we did not adopt the information to avoid confusion.

Neither surgical mortality nor bronchopleural fistula was observed in either arm among a total of 1105 major pulmonary resections. Recently, surgical mortality at a single institute after standard lobectomy was reported to be $0.3 \%$ based on 3270 surgical cases in Japan. ${ }^{12}$ In the American College of Surgeons Oncology Group trial, which was a multi-institutional, large-scale trial, it was $1.4 \% .{ }^{13}$ Our 
multi-institutional results compare favorably with those reports, demonstrating that outstanding outcomes are also possible in multi-institutional trials.

Intraoperative bronchial injury was observed in 1 patient (grade 1) in the lobectomy arm, and 6 patients (grade 1 in 5 patients, grade 2 in 1 patient) in the segmentectomy arm. In contrast, intraoperative injury of the pulmonary artery was noted more so in the lobectomy arm. However, no patients experienced bronchopleural fistula. A recent report suggested that the frequency of bronchopleural fistula is $0.94 \%$ based on a large-scale study of 34,000 surgical cases. ${ }^{14}$ Our results also confirm that an outstanding outcome can be achieved even by a multi-institutional study.

\section{CONCLUSIONS}

Based on data from our randomized trial comparing segmentectomy and lobectomy, the outcomes showed no difference in almost all postoperative parameters of intraoperative and postoperative complications, except segmentectomy was associated with higher chance of air leak.

\section{Conflict of Interest Statement}

Dr Suzuki reports grants and personal fees from Ethicon, Medtronic, Taiho, Eli Lilly, Kyowa Kirin, Teijin, and CSL Behring; personal fees from Intutive, Daiichi Sankyo, Gunze, AstraZeneca, and The Chemo-Sero-Therapeutic Research Institute; and grants from Shoen kai, Ezai, Shionogi, and Ono outside this work. Dr Saji reports personal fees from Boehringer Ingelheim, AstraZeneca, BristolMyers Squibb, Nihon Medi-Physics, Pfizer, Ethicon, Chugai Pharmaceutical Co Ltd, Taiho Pharmaceutical Co Ltd, and FujiFilm Medical Co Ltd outside this work. Dr Aokage reports personal fees from Covidien Japan (seminar presentations and editorial supervision), Johnson \& Johnson (interview on product development, video presentation, and seminar presentation), Taiho Pharma (writing), Teijin Pharma (seminar presentation), CSL Behring (writing and editorial supervision), Sano Hospital (surgical supervision), Uchio Clinic (medical supervision), Medela Healthcare (seminar presentation), Yokohama City University Medical Center (seminar presentation), and Konica Minolta (medical supervision) outside this work. Dr Watanabe reports personal fees from Ethicon Endo-Surgery Japan, a Johnson \& Johnson company; Covidien Japan; CSL Behring; Astellas; and Stryker outside this work. Dr Okada reports grants and personal fees from Astellas Pharma Inc, AstraZeneca Plc, Eisai Co Ltd, Merck Sharp \& Dohme, Otsuka Pharmaceutical Company Ltd, Ono Pharmaceutical Company Ltd, Kyowa Hakko Kirin Company Ltd, Medtronic, Sanofi SA, Daiichi Sankyo Company Ltd, Shionogi \& Company Ltd, Shimadzu Corporation, Johnson \& Johnson, CSL Behring KK, Taiho Pharmaceutical Company Ltd, Chugai Ro
Company Ltd, Takeda Pharmaceutical Company Ltd, Tsumura \& Company, Eli Lilly and Company, Nippon Kayaku Company Ltd, Boehringer Ingelheim GmbH, Nihon Pharmaceutical Company Ltd, Nihon Medi-Physics Company Ltd, Novartis Pharma KK, Pfizer Inc, Fuji Pharma Company Ltd, Bristol-Myers Squibb, Mochida Pharmaceutical Company Ltd, and Yakult Honsha Company Ltd outside this work. Dr Mizusawa reports personal fees from Chugai Pharmaceutical outside this work. Dr Tsuboi reports grants from AstraZeneca KK as well as personal fees from AstraZeneca KK, Eli Lilly Japan, Boehringer-Ingelheim Japan, Daiichi-Sankyo, Chugai Pharmaceutical Company Ltd, Taiho Pharma, Johnson \& Johnson Japan, Covidien Japan, Teijin Pharma, CSL Behring, Bristol-Myers Squibb Japan, and MSD Japan outside this work. Dr K. Nakamura reports personal fees from Taiho, Merck, Chugai, and Bayer outside this work. Dr Mitsudomi reports personal fees from AstraZeneca, MSD, BMS, Daiichi-Sankyo, KyowaHakko Kirin, and Johnson \& Johnson as well as grants and personal fees from Pfizer, Boehringer Ingelheim, Ono, Taiho, Eli Lilly, Chugai, and Covidien outside this work. Dr Asamura reports personal fees from Covidien Japan, Johnson \& Johnson, Shionogi Pharma, AstraZeneca, Novartis, Astellas Pharma, Taiho Pharmaceutical, Kyowa Kirin, Ono Pharma, Eli Lilly, and Chugai outside this work. All other authors have nothing to disclose with regard to commercial support.

Participating institutions (from north to south):

Japan Clinical Oncology Group

Sendai Medical Center, Tohoku University Hospital, Iwaki Kyoritsu Hospital, Ibaragi Prefectural Central Hospital, Tochigi Cancer Center, Gunma Cancer Center, Saitama Cancer Center, National Cancer Center Hospital East, Chiba University Hospital, National Cancer Center Hospital, Kyorin University Hospital, Tokyo Medical University Hospital, Tokyo Metropolitan Cancer and Infectious Diseases Center Komagome Hospital, Cancer Institute Hospital, Juntendo University Hospital, St. Marianna University School of Medicine, Kanagawa Cancer Center, Yokohama Municipal Citizen's Hospital, Yokohama City University Medical Center, Niigata Cancer Center, Kanazawa University Hospital, Saku Central Hospital, Shizuoka Cancer Center, Aichi Cancer Center, Nagoya University Hospital, Kyoto University Hospital, Osaka University Hospital, Kindai University Faculty of Medicine, Osaka Medical Center for Cancer and Cardiovascular Diseases, Osaka City General Hospital, Osaka Prefectural Medical Center for Respiratory and Allergic Diseases, Kinki-chuo Chest Medical Center, Osaka City General Hospital, Hyogo Cancer Center, Kurashiki Central Hospital, Okayama University Hospital, Hiroshima University Hospital, Kure Medical Center, Shikoku Cancer Center, Kyushu Cancer Center, Fukuoka University Hospital, Nagasaki University Hospital, Kumamoto University Hospital, Kumamoto Chuo Hospital, Oita University Hospital, and Okinawa National Hospital. 


\section{West Japan Oncology Group}

Kitasato University Hospital, Kanagawa Cardiovascular and Respiratory Center, Sagamihara Kyodo Hospital, Toyama University Hospital, Ishikawa Prefectural Central Hospital, Gifu City Hospital, Hamamatsu Medical University Hospital, Serie Hamamatsu General Hospital, Aichi Cancer Center Aichi Hospital, Nagoya Medical Center, Nagoya University Hospital, Nagoya Elishia Hospital, Shiga University of Medical Science Hospital, Osaka University Hospital, Osaka City University Hospital, Kinki University Hospital, National Tone Yama Hospital, Rinku General Medical Center, Suita Municipal Hospital, Kobe University Hospital, Kobe City Medical Center General Hospital, Hyogo Medical College University, Hyogo Prefectural Awaji Hospital, Himeji Red Cross Hospital, Kawasaki Medical School Hospital, Hiroshima City Hospital, Hiroshima City Asa Hospital, Yamaguchi Ube Medical Center, University of Occupational and Environmental Health, Nippon Steel Yazata Memorial Hospital, Iizuka Hospital, Saga University Hospital, Kumamoto University Hospital, Kumamoto Regional Medical Center, Saiseikai Kumamoto Hospital, and Oita Prefectural Hospital.

\section{References}

1. Ferlay J, Soerjomataram I, Dikshit R, Eser S, Mathers C, Rebelo M, et al. Cancer incidence and mortality worldwide: sources, methods and major patterns in GLOBOCAN 2012. Int J Cancer. 2015;136:E359-86.

2. Asamura H, Goya T, Koshiishi Y, Sohara Y, Eguchi K, Mori M, et al. A Japanese lung cancer registry study: prognosis of 13,010 resected lung cancers. $J$ Thorac Oncol. 2008;3:46-52.

3. Goya T, Asamura H, Yoshimura H, Kato H, Shimokata K, Tsuchiya R, et al. Prognosis of 6644 resected non-small cell lung cancers in Japan: a Japanese lung cancer registry study. Lung Cancer. 2005;50:227-34.

4. Sawabata N, Miyaoka E, Asamura H, Nakanishi Y, Eguchi K, Mori M, et al. Japanese lung cancer registry study of 11,663 surgical cases in 2004: demographic and prognosis changes over decade. J Thorac Oncol. 2011;6:1229-35.
5. Ginsberg RJ, Rubinstein LV. Randomized trial of lobectomy versus limited resection for T1 N0 non-small cell lung cancer. Lung cancer study group [see comments]. Ann Thorac Surg. 1995;60:615-22.

6. Okada M, Koike T, Higashiyama M, Yamato Y, Kodama K, Tsubota N. Radical sublobar resection for small-sized non-small cell lung cancer: a multicenter study. J Thorac Cardiovasc Surg. 2006;132:769-75.

7. Tsubota N, Ayabe K, Doi O, Mori T, Namikawa S, Taki T, et al. Ongoing prospective study of segmentectomy for small lung tumors. Study Group of Extended Segmentectomy for Small Lung Tumor. Ann Thorac Surg. 1998; 66:1787-90.

8. Asamura H, Hishida T, Suzuki K, Koike T, Nakamura K, Kusumoto M, et al. Radiographically determined noninvasive adenocarcinoma of the lung: survival outcomes of Japan clinical oncology group 0201. J Thorac Cardiovasc Surg. 2013;146:24-30.

9. Suzuki K, Asamura H, Kusumoto M, Kondo H, Tsuchiya R. "Early" peripheral lung cancer: prognostic significance of ground glass opacity on thin-section computed tomographic scan. Ann Thorac Surg. 2002;74: 1635-9.

10. Suzuki K, Koike T, Asakawa T, Kusumoto M, Asamura H, Nagai K, et al. A prospective radiological study of thin-section computed tomography to predict pathological non-invasiveness in peripheral clinical IA lung cancer (JCOG0201). $J$ Thorac Oncol. 2011;6:751-6.

11. Nakamura K, Saji H, Nakajima R, Okada M, Asamura H, Shibata T, et al. A phase III randomized trial of lobectomy versus limited resection for small-sized peripheral non-small cell lung cancer (JCOG0802/WJOG4607L). Jpn J Clin Oncol. 2010;40:271-4.

12. Watanabe S, Asamura H, Suzuki K, Tsuchiya R. Recent results of postoperative mortality for surgical resections in lung cancer. Ann Thorac Surg. 2004;78: 999-1002.

13. Allen MS, Darling GE, Pechet TT, Mitchell JD, Herndon JE II, Landreneau RJ et al. Morbidity and mortality of major pulmonary resections in patients with early-stage lung cancer: initial results of the randomized, prospective ACOSOG Z0030 trial. Ann Thorac Surg. 2006;81:1013-9.

14. Pforr A, Pages PB, Baste JM, Thomas P, Falcoz PE, Lepimpec Barthes F, et al. A predictive score for bronchopleural fistula established using the French database Epithor. Ann Thorac Surg. 2016;101:287-93.

Key Words: intentional sublobar resection, complex segmentectomy, prognosis, morbidity 